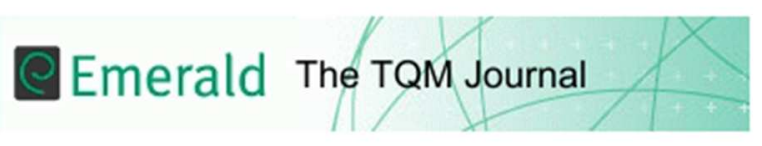

\title{
A holistic framework to embed good company practice for customer retention
}

\begin{tabular}{|r|l|}
\hline Journal: & The TQM Journal \\
\hline Manuscript ID & TQM-11-2015-0139.R1 \\
\hline Manuscript Type: & Research Paper \\
\hline Keywords: & $\begin{array}{l}\text { Customer Service, Customer retention, Continuous Improvement, } \\
\text { Organizational Culture, Delphi technique }\end{array}$ \\
\hline \multicolumn{2}{|l}{} \\
\hline
\end{tabular}


Figure 1. 4-P Cycle of CI. (Adapted from Buelens et al., 2002, p. 8)
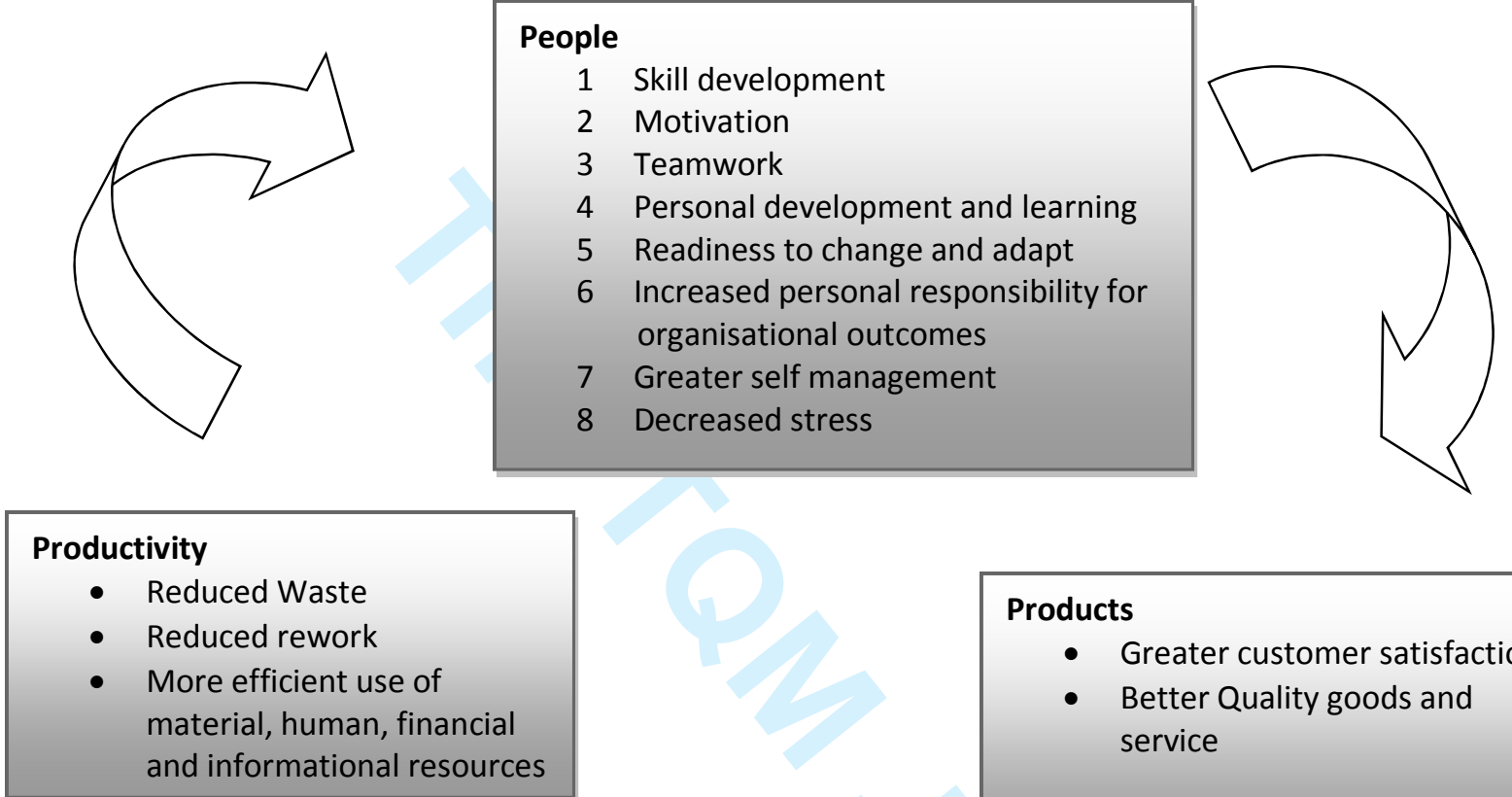

\section{Products}

- Greater customer satisfaction

- Better Quality goods and service
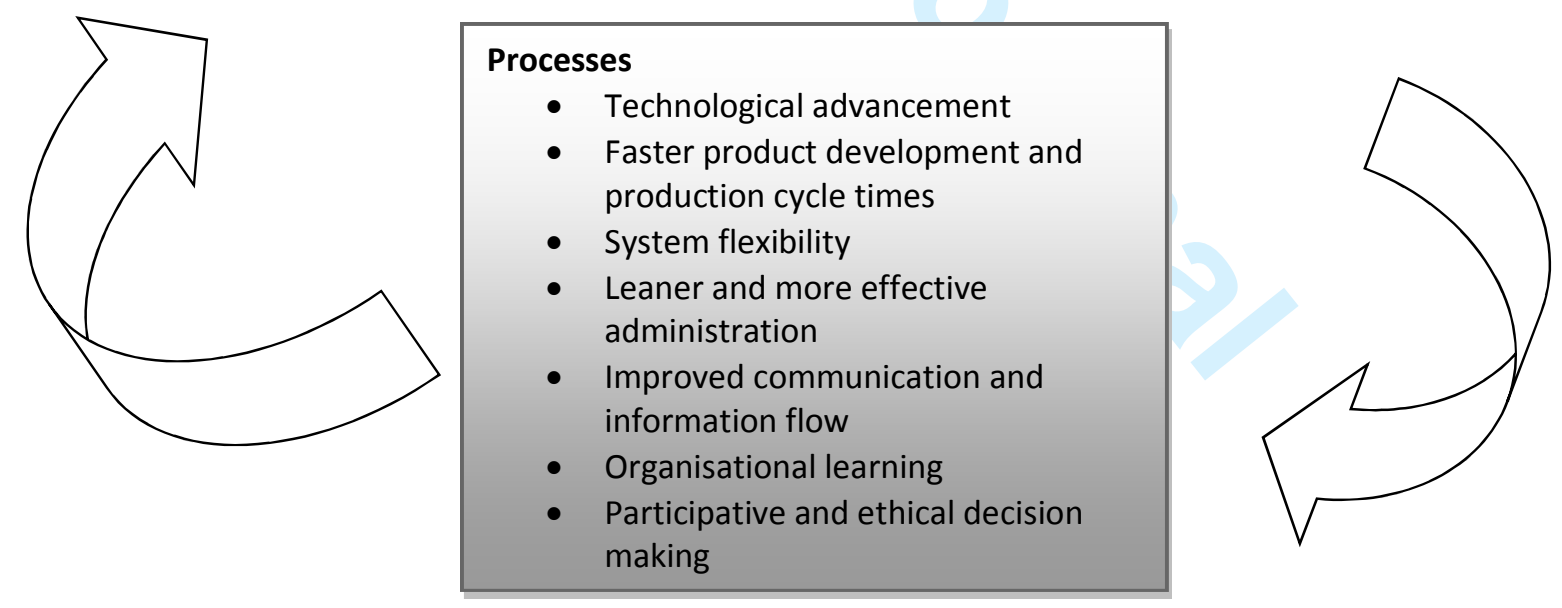
Figure 2. The key elements of world class service (Adapted from Daffy, 2001, p. 223)
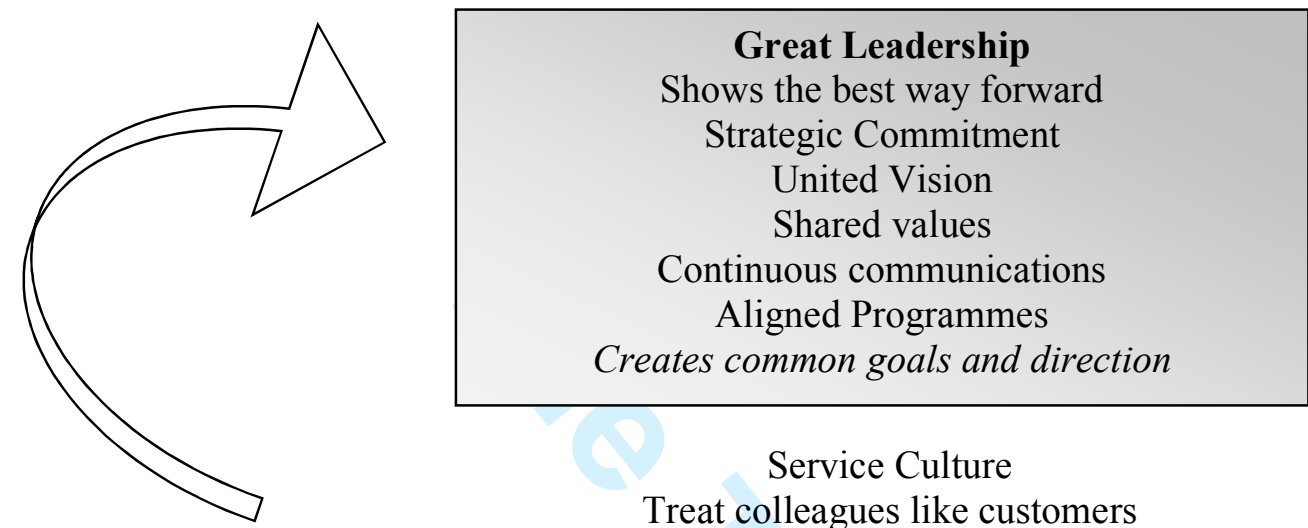

Service Culture

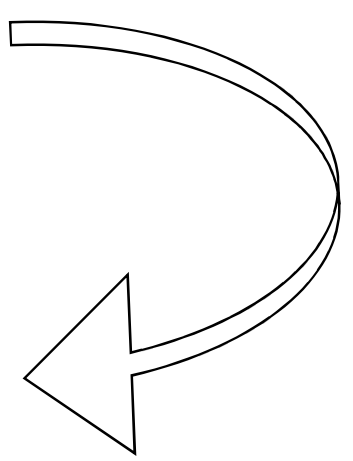

Treat colleagues like customers

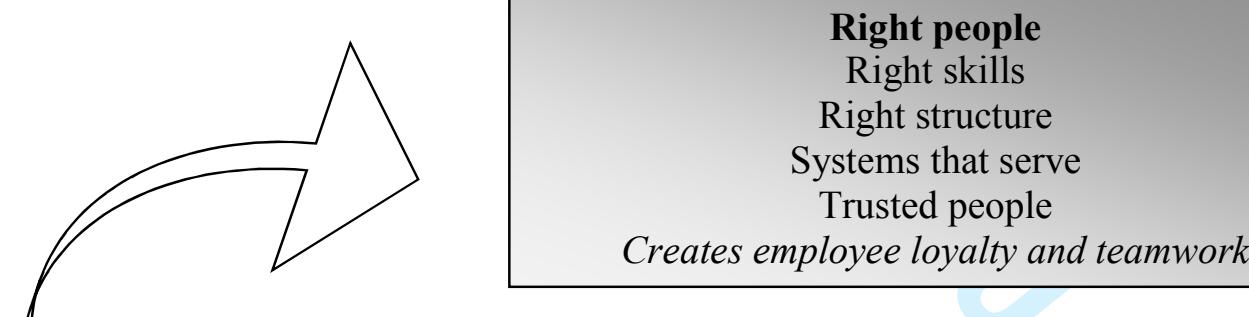

Right people

Right skills

stems that serve

Creates employee loyalty and teamwork

\section{Winning pace}

Outpace competition

Whole company involvement

Regular ideas sessions

Rewarding the right way

Creates a Virtuous cycle

\section{CI}

Never becoming complacent Eliminate waste Simplify processes Continuous feedback Benchmark continually Creates an ever improving environment
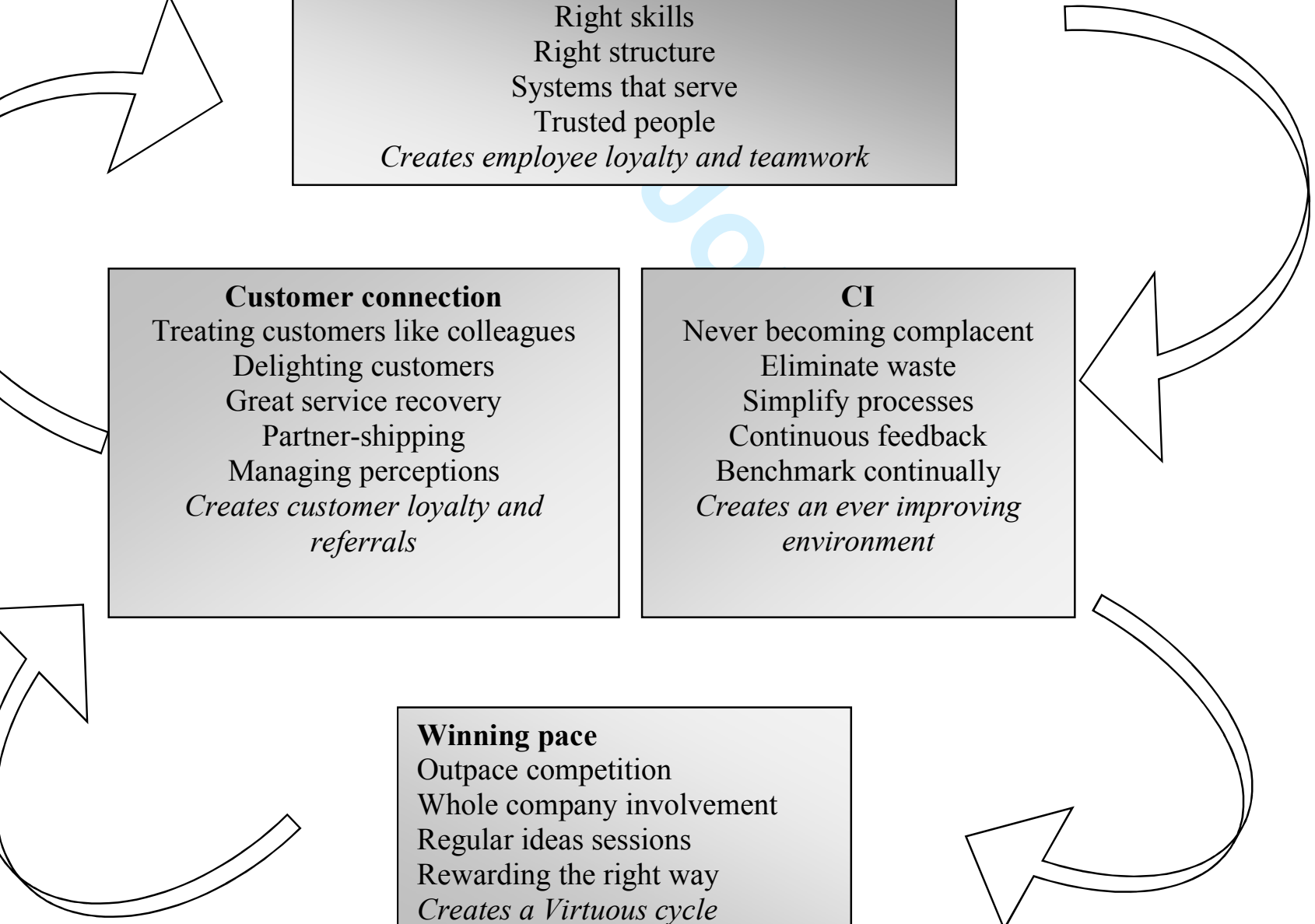
Figure 3: Initial framework

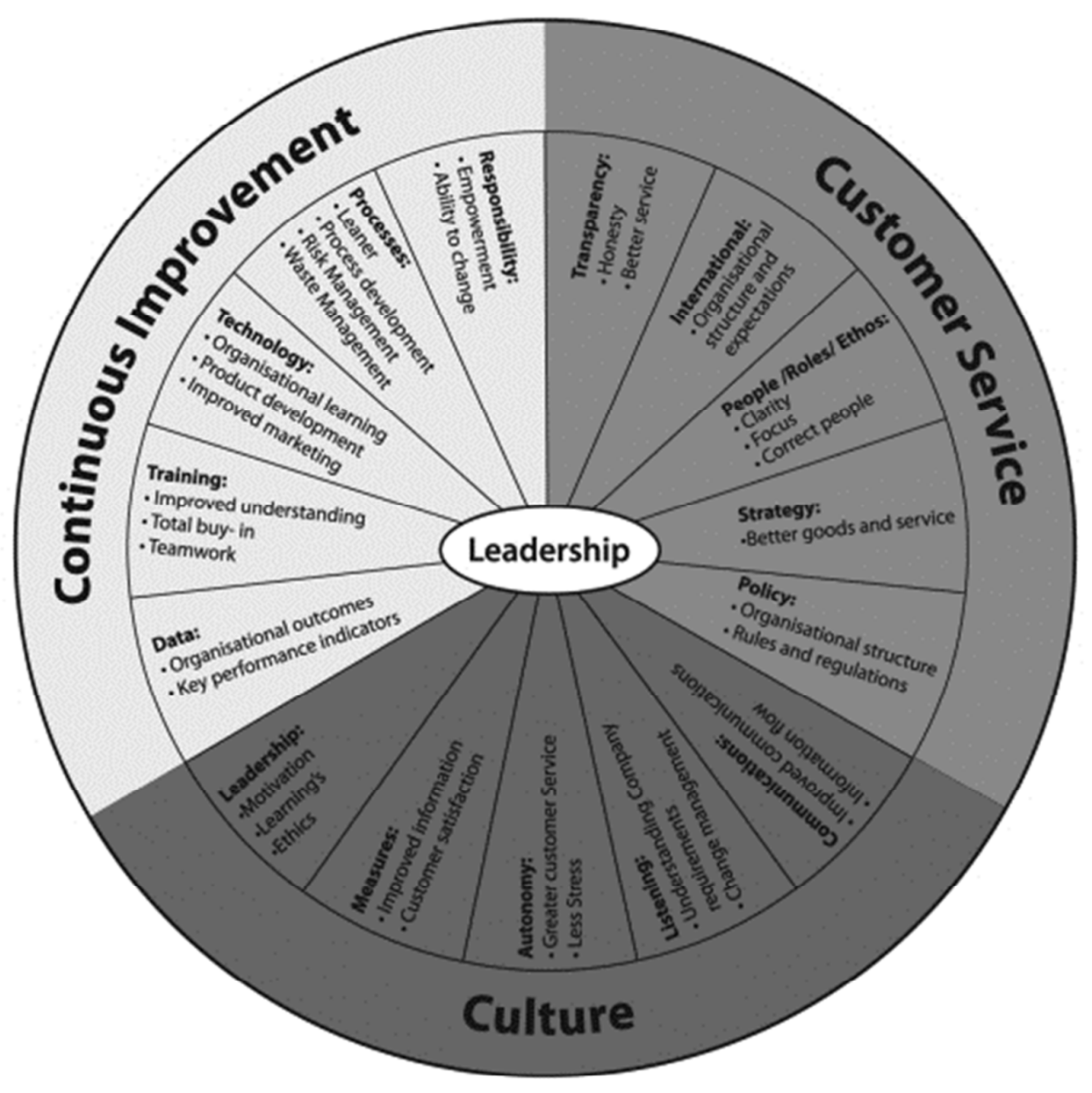


Figure 4: the final framework

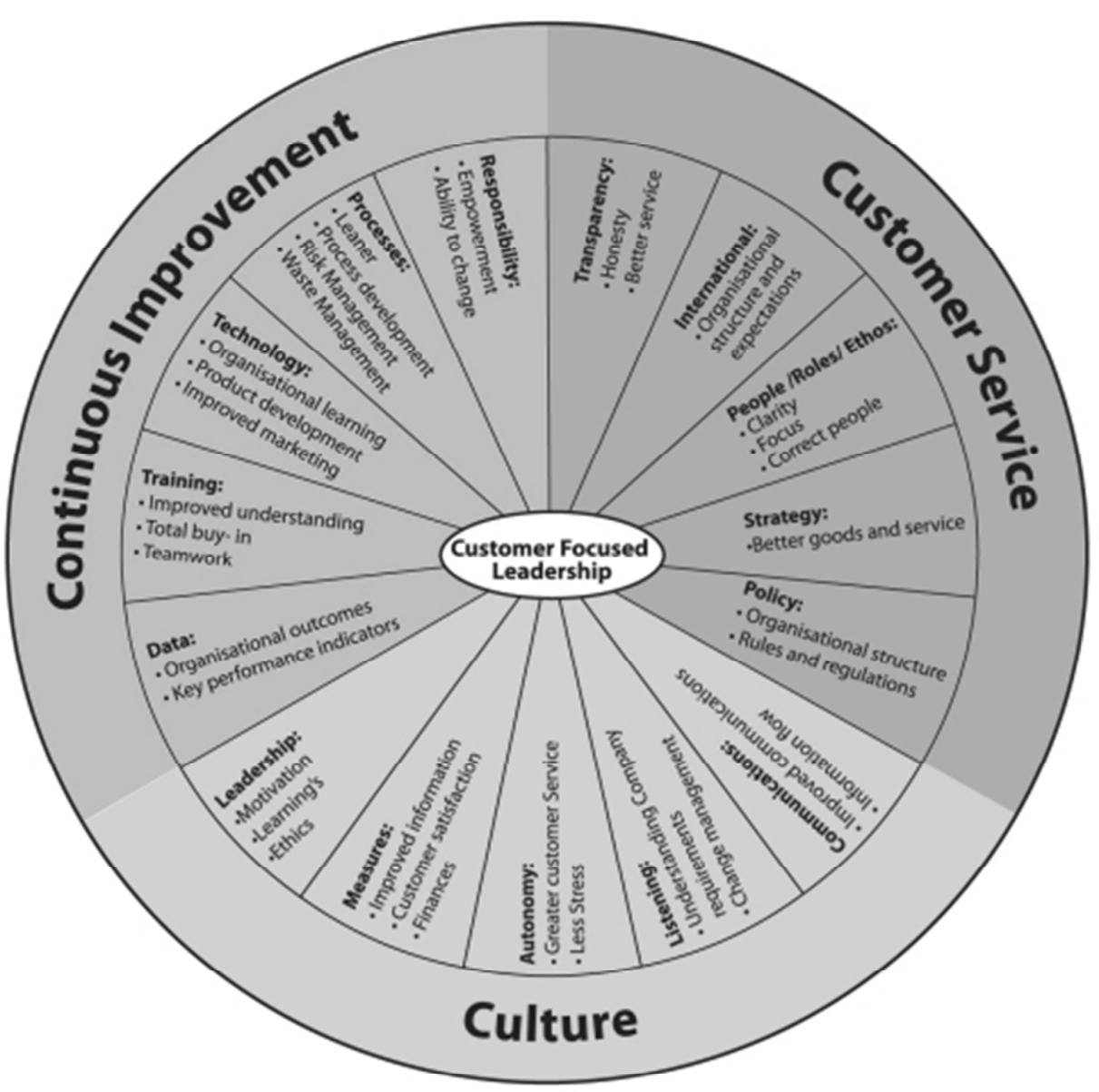




\begin{abstract}
Purpose - To detail a holistic practice based guiding framework for improving customer retention, which helps companies instil a customer service culture through encouraging them to concentrate on the three key areas of culture, continuous improvement and customer service.
\end{abstract}

Design/Methodology/approach - The Delphi technique, in the form of a qualitative and systemised approach to data collection that incorporated in-depth semi-structured and structured interviews at director level across a range of industries using 3 rounds of hour long in-depth semi-structured interviews at director level across a range of industries. This was done with 9 directors, totalling over 30 hours of data requiring in excess of 200 hours to $\underline{\text { transcribe.. }}$

Findings - In order to achieve customer retention, a holistic company approach underpinned by senior management buy-in is critical, with open communication, employee empowerment, and employing 'the right' personnel. The framework is viable with specific organisation input and supplementation with ongoing customer research.

Research limitations/implications - The framework has only been tested with the companies in the study, and requires testing in practice. As such, it has not covered the ability of companies to change, but has simply developed a framework to assist in identifying the areas that need to be reviewed when considering changing to focus on the customer.

Practical implications - To use this approach to customer retention requires companies to amalgamate culture, customer service and continuous improvement equally alongside customer focused leadership, as an underpinning for the ethos of the business.

Originality/value - The Delphi technique in an in-depth systemised approach with directors revealed unanticipated and significant insights regarding the benefits of amalgamating and devoting equal weight to the three areas of culture, customer service and continuous improvement to improve quality in all these areas

\title{
Introduction: context and value
}


This paper details the development of a practice based guiding framework to improve customer retention ${ }_{2}$. This framework is intended to be a mechanism for companies to focus on the key areas and steps to instil a customer service culture and thuse improve-customer retention by improving organizational performance (cf. Rezaei et al. 2015). Customer retention is key, particularly in today's highly competitive post financial crisis world. Yet, research suggests that $70 \%$ of leaving customers leavedo se due to poor customer service (Rich, 2009; Tayfon, 2006; US Chamber of Commerce, 2006; Thomas 2003; Thompson, 2005; Daffy, 2001; Mintel, 1999)_and attracting customers costs significantly more than retaining customers (Ennew et al., 2015). Literature-exists in-a number of related fields (including Organisations, Customer Service, Continuous Improvement, Company Culture and Competitive Advantage) suggestsreveals three key areas forto instilling a customer service culture:

1. Continuous Improvement (CI)

2. Customer Service

3. Company Culture

RegardingIn terms of the role CI plays in implementing a good customer service strategy, numerous a number of different models exist (e.g. Buelens et al, 2002). These models agree that creating a customer service environment requires the correct people, management, processes, and the capacity for internal change. Nevertheless, some-of the models are more process and procedure driven, and could potentially neglect people through their focus on cost savings (e.g. Kee-Hung and Cheng, 2009).

IFurther, in the area of customer service writers such as Cook (2008), Wellington (2010), Deming (1991), Heskett et al., (1997), Marsh (1998) and Juran (1989 and 2003) have developed models to help instil a customer service culture, but these often-fail to meet the ideal 'Goldilocks' principle of being 'just right'. They tend to be either too simplistic (e.g. Buelens et al, 2002), or too complicated (e.g. Wellington, 2010) to enable linkages to be made. Nevertheless, two models help show links between CI (Beulens et al, 2002 (see figure 1 below) and Customer Service (Daffy 2001) (see Figure 2). These models' depth and focus echoo with many areas mentioned in the literature. Most importantly, they take a holistic approach and include culture and leadership, which is noted as key in much literature (cf.e.g. Baird and Parasnis, 2011; Buelens et al, 2002; Daffy, 2001; Gratton, et al., 2003; Rowlands, 2008; Suzaki, 2002) something key at every customer interaction or touchpoint (Rawson et al, 2013; Sleep et al., 2015). 


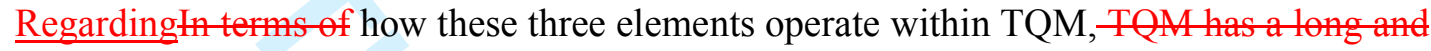
much lauded history of research and implementation and the early work of Deming (1991) and Juran (1989) is still-very much-in used today. Sashkin and Kiser (1993) describe TQM as consisting of a three pronged approach:

1. Training in the tools available to solve issues and improve processes (i.e. CI).

2. The customer must become the centre of the process (i.e. customer service)

3. Company culture should be one of agreed values and leadership direction (i.e. culture).

In order for companies to perform TQM to the optimum these three elements must be aligned (Green, 2012) $\bar{y}_{2}$ and-within a holistic approach (Kohlbacher and Reijers, 2013; Gîfu and Teodorescu, 2014). Conversely, companies could-in fact damage their strategy by not consideringtaking into account these-above areas of business functionality (Asif et al, 2009; Harvard Business Review, 1999; Ishikawa, 1990) and even create counterproductive workplace behaviours, (Johnson, 2015) potentially damaging customers' experience. Criticism is still aimed at TQM is still criticized foras not being sufficiently customer, or new customer (Parast, 2011; Cao et al 2015) focused, nor having a company culture to support it (Dahlaard, 2006; Irani, 2004; Godfrey et al., 2002). Surviving cCompanies that will survive oftentend to have cultures that embrace people empowerment (Williams, 2008), strong leadership (Rowlands, 2008; Carter, 2013; Lam et al. 2015) or influential (Löfving, 2016) leadership $_{,}$, flexibility in its people and processes (Beulens et al. 2002), and hold high ethics, and quality policies (Asif et al. 2009). Furthermore, they understand the importance of gathering and using relevant information (Beanstock et al. 2015) that is customer focused (Saarijärvi et al 2015). This paper adds to the field by presenting a holistic model that amalgamates and givesdevotes equal weight to the three areas of culture, customer service and continuous improvement-throughout all areas of a business to help instil customer retention. 
The paper now reviews some-of the literature-and models in these fields-of customer service, continuous improvement and culture. ThenFollowing this, the methodology of how the Delphi technique was used to gather data to develop an empirically based framework (to complement existing literature based ones (e,g,Chakravorti, 2011) is described. Next, the findings are presented and discussed before the final model is shown.

\section{Continuous Improvement, Customer Service and Company Culture}

Much-literature aimed at Customer Retention literature exists in the fields of Continuous Improvement, and Customer Service. In this literature, three important areas are highlighted: Continuous Improvement (CI), Customer Service, and Company Culture (also referred to as Organizational Culture). It isThe literature generally agreeds that companies must gather relevant information about both internal and external customer needs (Berry and Parasuraman 1991, Suzaki 2002, Buelens, et al. 2002; Griffin et al. 2012) in an endeavour to achieve sustainability and a competitive advantage (Ireland et al., 2012; Williams, 2008; Gremler et al., 2001; Gupta, 2016). Indeed, "there can be no long-term success without satisfied customers" (Chaneski, 2015, p.42). To achievede this, however, requires an established culture of 'delighting customers' (Daffy, 2001; Carter et al. 2013; Chidley and Pritchard, 2014) with clear staff direction, strong leadership, unambiguous policies and procedures, excellent communication, and training programmes to improve skills and instil employee empowerment-are required (Williams, 2008; Porter, 1998; Conway and Briner, 2015; Li et al, 2015). Indeed, employees' knowledge can help identify Critical Success Factors for managing quality (Calabrese and Scoglio, 2012). Business improvement models such as TQM or Lean (Womack and Jones, 2003; Laureani et al, 2010), and Six Sigma (Parast, 2011), although keypart of the process, arguably do not complete the whole process as . This is partly because it has been argued that they can be somewhat process driven and less customer focused (Dahlaard, 2006; Irani, 2004; Godfrey et al., 2002), and complex processes may require the amalgamation of many approaches (Assarlind et al, 2012).

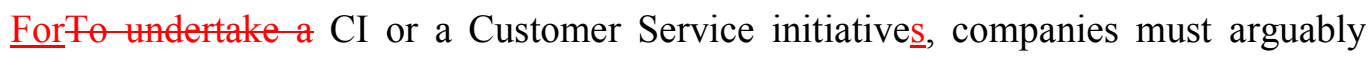
consider all areas_of in relation to customer experience, ensuring-all employees understand customer needs, and are able and empoweredhave the capabilities and empowerment to address them (Oliver, 1999; Want, 2003; Pantouvakis and Bouranta, 2013). Althoughugh it is acknowledged that employing the 'right person' is considered the most important asset to a company, actually identifying and keeping them 'right people' is-a challenginge (Soderlund 
and Rosengren, 2008). Also, ensure employee job satisfaction is key to boosting service quality (Hur et al., 2015; Lages and Piercy, 2012, Yang et al. 2016), particularly with toxic customers (Kumar Madupalli and Podder, 2014). Furthermore, rewards, targets and measurable KPIs must recognise the customers within the system and procedures must align with the company strategy (Laursen and Thorlund, 2010; Parmente, 2007).

Company culture consists of many facets and can impact on all business areas. Research shows that companies with a CI customer focused culture, values and norms tend to be more successful (Want 2003). Thus, companies must motivate employees by setting clear guidelines surrounding their values and norms that must be followed to achieve this culture (Want 2003).Organizational change is inextricably linked with organizational culture: without the culture of change some argue that change will not happen (Alvesson and Sveningsson, 2015).

Nevertheless, Yet despite all of the above, and arguably having a knowledge of all of the above, many companies still focus on sales, manufacturing and profit rather than customers. This can be seen in key models in the field.

Two key models in this area are Beulens et al's (2002) model of the 4 P Cycle of CI (see Figure 1 below) and Daffy's Key elements of World Class Service Model (see Figure 2 below).

\section{Insert Figure 1 Here \\ Insert Figure 2 Here}

Although key models in their area, neitherboth fail to holistically represent-a ways forward for companies to inculcate a customer service culture for customer retention. Beulens et al's model is arguably somewhat simplistic in its implications. For example, when-it describinges how the customer-will feelings or the-it describes the delivery of quality goods and services, these are merely statements, whereas and in other parts of the cycle the model describes necessary the actions that need to be taken such as developing skills, or increasing responsibility. In terms of Daffy's Key Elements Model, this arguably places more emphasis on-the customers throughout and highlightthroughout, highlightings the importance of the different elements, although they are treated discretely rather than holistically.. However, these elements are nonetheless treated diseretely and there is thus a danger of the focus being dissipated away from the customer towards profit. Furthermore, Porter (1998) also advises 
againsteaution regarding the error of potentially jumping from one strategy to another, as this reduces focus. takes the focus away from implementing any one strategy correctly.

Despite suchtheir shortcomings, both models are key-in the field, and also resonate withreflect (and are reflected by) much of the literature. With regard to-Beulen's et al.'s (2002) model's focus on, the impertance of having the right people is echoedalso reflected in many sources (e.g. Schein, 2004; Rowlands, 2008, France et al., 2009) as are the importance of productivity (Zeithaml et al, 1990; Gratton et al, 2003), products (Heskett et al, 1997, Suzaki, 2002) and processes (Baird and Parasnis, 2011, Rowlands, 2008). In terms of Daffy's model, and in line with much of the literature_-leadership is much emphasised (cf. Gratton et al., 2003; Pride, 2008), aided by gathering and listening to customer feedback (Zeithaml et al., 1990; Rowlands, 2008; Dabholkar, 2015). The use of up to date technology (Baird and Parasnis, 2011) and now the use of social media (Agnihotri et al. 2015) is also considered key. Also for companies operating across many cultures, processes may need to consider different cultural practices (Mobley et al. 2009; Leatherman, 2008; Webster and White, 2010)

The research in this paper combined the three elements of: Beulens et al's (2002) model, Daffy's (2001) model, and existing literature to formulate questions for in-depth Delphi interviews with company directors. We now describe the rationale and approach to these interviews. the underpinning rationale and approach with these interviews before moving to our findings and the framework.

\section{Methodology: interviews using the Delphi technique.}

The data to form the framework was gathered using three iterative rounds of interviews with 9 experts from companies of differing sizes and all from different industries. $\Lambda$ broad industry view was sought largely due to the aim of producing a framework guide that could be used in the general business marketplace. At each round the data gathered was shared with each interviewee and new opinions were sought, with the aim of reaching a consensus on the value of the data for all concerned. This process of reporting back after each round is known as the Delphi technique. The Delphi technique is named after the Ancient Greektakes its name from the Ancient Greek fount of knowledge, the Oracle, situated at Delphi. It, and is a qualitative, yet structured and systemised approach-that aimeds atte gaining the most reliable consensus of opinion (Powell 2003; Woudenberg, 2001). The technique dates back to 1948 when it was first used in forecasting and planning, (Gupta and Clarke, 199ㅁ6; Woudenber, 1991): and-It gained popularity in the 1970 s as a method of research investigation or a 
communications device (Woudenberg, 1991) that moved away from purely quantitative methods into the qualitative arena, and involved a number of anonymous interviews with experts (Rowe and Wright 2001), semi-structured or structured, to elicit the opinions of industry experts (Browne 1968).

ItThe Delphi technique has manya number of advantages $;$ - Its anonymity encourages discussion, yet as participants understand the fact that people know the information will be shared and that feedback will be given over multiple interactions, ${ }_{2}$-ncourages reflection and consideration are encouraged (Salkind, 2010). Its use of experts draws on an immense range of experience when the total experience of all individuals is accounted for (Rowe and Wright, 2001). Further ${ }_{2}$ the fact that it uses several rounds of data collection, interviews -helpings reach a-consensus and increases reliability (Salkind, 2010) $;$, $\mathrm{P}$-with participation leadsing to ownership ${ }_{2}$ and possiblyean result in the implementation of changee by the participants (Woudenberg, 2001), especially asgiven the fact that the feedback-process allows participants to widen their knowledge (Salkind, 2010).

Commonly, Delphi studies are done using questionnaires (Saizarbitoria et al 2006), surveys or database analyses. Saizarbitoria (2006) summarizes numerous Delphi studies, 11 of which drew on surveys and 7 of which used databases. Such studies have the advantage that the data gathered can come relatively straightforwardly from large numbers of participants (e.g. 100) and also yields itself to ready analysis through the use of electronic software such as QSR Nvivo. Despite these advantages, the Delphi technique is not without its drawbacks. Logistically it places immense time demands on both participants and researchers, but the richness and depth of the data it gives arguably outweighs these drawbacks.

In contrast, terms of the process of how data was gathered for this project used,-three rounds of $\underline{\text { in-depth interviews with } 9 \text { industry expertsts were undertaken. Thus, } 27 \text { interviews }}$ were conducted totalling more than 30 hours in length. Such a large amount of data took over 200 hours to transcribe but had the advantage of containing extremely Although only 9 industry experts were interviewed, the-richness of the information to-gathered assisted in help reaching an overall consensus after the final round. The transcripts were analysed through continual reading and rereading in a themed analysis. Whilst having the advantage of more than meeting the recommendations of the number of interviews (Rowe and Wright, 2001 recommend 2) and minimum number of interviewees (Woudenberg 2001 recommends 6) there are nevertheless limitations. One of the main criticisms is the vast amount of time and cost required to gather and analyse the data (cf. Taylor, 2008). 
TAlso, the experts selected were arguably a convenient sample (Anderson, 2003) chosen because of the fact they were known to the researcher, and for their experience as company directors. The experts were asked to respond with a management/director level viewpoint and were assured of their anonymity. The framework (see figure 3 below) was developed based on the data gathered from the first two sets of interviews, the models (figure 1 and 2) and the literature-review. Q-The interview questions-were focused on the identified 3 key areas-as indicated from the literature-review: Company Culture, Customer Service and CI. The first round of questions were semi-structured to allow for expansion and probing (Teche, 1990), -t the second-round of questions was more detailed and specific, with. The questions-were developed from the findings from round one and shared-in turn with each interviewee. Feedback, opinion, and answers were discussed. In the third-and final interview the framework was shown to elicit industry expert opinion as to the suitability and ease of its use of the framework in practice.

\section{Findings and Discussion}

Our results and discussion section is divided into two parts. The first part of our findings and discussion presents and considers the results from the first two interviews relating to the three main areas of Customer Service, Culture, and Continuous Improvement_. It is these three areas that the developed framework centred on. TThis framework is presented and discussed in the second part presents and discusses where the results from the third and final Delphi interview-are presented and discussed $\mathrm{to}_{2}$ showing the reactions of the industry experts to the framework. Our dPiscussion focuses both on comparesisons with the literature and ourwith industry expertsexperts' views ${ }_{2}$-on and in particular considering implications involved with the framework's practical implementation-of the framework to instil a eustomer focused approach throughout all levels and areas of the company.

\section{Customer Service,}

RegardingIn terms of Customer Service, the areas of 'competitive advantage', 'people' and 'local knowledge' were-either considered-beneficial or integral to delivering customer service. With regard to the area of 'Ceompetitive advantage' was noted to be key, it was noted by by the majority of companies tothat delivering effective customer servicee was key to giving the company a competitive advantage (cf. Want, 2003; Aula, 2016). Consequently, customer service was held as a core competency and considered by the majority of companies 
to be the ethos of the business (cf. Deming, 1991; Wellington, 2010). TIt was felt that the leadership team needed to believe in a clearthe policy, explain-it, mentor-it, train and support employees (cf. Li et al, 2015), and. It was also felt that there had to be a clear policy and that an atmosphere that encouraged questions, and feedback-and-support that incorporated continuous monitoring and training was needed (cf. Williams 2008). In interview 2, all nine respondents expressed the idea this was "up to the whole company" and the responsibility of "anybody with a touch-point with customers both internally and externally" to look after clients (Sleep et al., 2015). The achievement of $\underline{S}$ such a competitive advantage could bewas alse linked in with salaries and promotion... Regarding salaries, Oneene company noted that: "our customer service policy is used throughout the company as a measure of competitive advantage and salary advancements. We talk about it all the time". In terms of promotion, theyis company commented that “all our staff are measured against the company's core values on a continuous basis and it becomes a competitive advantage for them if they are applying for an internal role-and is a constant reaffirmation of what we are here to do [and] in order to do this, employees must understand, accept and live by the company core values". One factor that arose in the Delphi interviews but is not considered in the literature as far as we can see, is the issue of transparency. One company stressed the importance and presence of transparency, noting that "We have a complete transparency policy, we are completely open with our clients and assume they are with us, it helps to build trust in the partnership, and we always let them know what's going on" and felt openness builds trust. another felt transparency was important.

HThe theme of having the 'right people' was also considered critical to achieving customer service (Soderland and Rosengren, 2008) and. As one company noted, "it's down to the people you employ to look after your customers,", or,. Another company further noted that, "no matter what policy you have in place, the wrong people may not follow your policies". Although not emphasised in the literature, in our Delphi interviews, Regarding employee selection_was a critically important element, and a minimum of two interviews was suggested, with continuously questioning the candidate to attain the truth, to "be specific, use examples and-probe and probe until you are comfortable with the answers". Experience and personality were considered potentially-of more valuablee than education ${ }_{-\bar{s}}$ and it was felt appraisals related to delivery of the company's core values were an excellent idea, and these should include consideration of examples where employees had delivered excellent customer service. 
In terms of the importance of local knowledge, all companies agreed that local knowledge was essential and that one process will not work across all cultures. For example, two companies commented on differences in customer service approaches in different countries, and that in one country "if they [the customer] do not complain then we don't have an issue". This respondent said that they were trying to change this thought process but were struggling to get agreement on any changes.

\section{Organisational Culture}

Similarly to how leadership was key to delivering customer service, it was also considered key to shaping the culture of a company to a service focused culture. Overall, the themes of leadership, communication, people and information were also prominent in the area of culture (cf. Rowlands, 2008). In terms of leadership, this was considered key by all companies, and it was felt directors and key managers needed to agree with the policy on culture. It was felt that directors must support the workers and show, or direct, rather than dictate. However, directing rather than dictating, although important, this was easier said than done:-; as one company noted that "it's actually quicker and easier to tell people what to do, but not necessarily the right thing to do". In interview 2, all companies agreed with the statement from interview 1 that " $y ¥ o u$ need to have the directors on board, if they believe in it and get behind it, it will work, but they need to keep control of it". Further, that this was essential, for example, saying that "Leadership is the key in implementing any new objectives" (cf. Leatherman, 2008). However, issues related to the exact manner of this leadership were complex. It was felt a "bullying atmosphere" could createlead to disloyalty and-create a negative working environment. Also, ${ }_{2}$ it was felt that if there was, "too much control in place you show a lack of trust" (cf. Want, 2003). It was believed that company employees will follow the attitude of the directors therefore the delivery of internal customer service is also important. er person responsible for customer service and therefore reaching agreement that customer service is a key component for business success was required. However, although in interview 2 everyone agreed with the interview 1 statement that "we need to be joined at the hip in terms of good customer service; it's at the heart of what we do", there was also a feeling that this would be something that was aspired to rather than something the company actually did. However, fit was also felt that most directors will have moved away from understanding the day-to-day workings of the business, and that in order to set out clear 
plans, targets, training and feedback it was necessary to listen to employees' opinions. the opinions of the workers as they will then potentially assist in implementing the changes given that their opinions had been sought and considered.Thus, the Delphi interviews highlighted the challenges directors face when attempting to practically implement a different way of working, and arguably such ways can only be implemented when they are done so holistically. Although directors here said they would aspire to do this rather than actually do it, they also felt that using the developed framework would help overcome these challenges.

CIn addition, communication was also considered to be fundamentally important and something that every department had to be involved in (cf. Haren, 2005). For example, In the words of one company, “aAll departments need to be involved, otherwise it just won't work, what is the point of have a singular customer service policy for one department; they all need to be involved and take responsibility". C- Furthermore, it was felt that communications should be circular, therethat there "should be a circle of communications with all departments interacting with each other". RegardingWith regard to company policy on communications, it was felt that companies need to have and communicate very clear values and competencies. and communicate them right from the start. Further, in line with the above ideas that there should be no bullying and that company policy should not be dictated, communication should be open: "tFhere needs to be an open interactions policy and method of communications and exchanges." Interestingly, though, one company added that "the intranet will not allow for this." andIndeed, in interview 2, when presented with the comment from interview 1 that "our customer service policy is sent out by the company intranet, we expect everybody to read and implement it." a Alllt the other-eight companies did not feel the intranet was sufficient (contra. Baird and Parasnis, 2011). Statements such as "ridiculous", "absolutely not”-“, "It's too important” and "it's unlikely to be enough" were used. All eight agreed that the intranet or emails-were useful in their own right, but tended to be ignored depending on how busy people were. They also agreed that communication mechanisms used reflected on the importance placed on the task and the use of "emails would not suitably reflect the importance of any [internal] communication regarding customers or policies".

Regarding the area of 'people', it was felt by all companies felt that people are crucial and that they must understand, accept and live by the company's core values_(Soderland and Rosengren, 2008). For exampleOne company stated: "employees need to understand that if we have no customers they won't have a job, but it's up to the directors to help them understand this and how to go about keeping their customers happy." There was a tension between empoweringvaluing people yete and emphasising their importance but at the same 
time not allowing them complete freedom, and the idea that any changes to working practices mustneeded to be agreed in advancebefore being allowed. As one company noted, "if changes need to be made then as a company they should be discussed and made, I do think however any changes need to be agreed before [being] implemented otherwise there could be bedlam."___ It was also-generally felt that not all employees would be happy with all the changes that would be implemented, and that for those who did not come on board even after retraining, then dismissal was considered appropriate. -Thus, the Delphi interviews revealed the importance of such personal elements as these, and the use of technology, which are not considered in the quality management literature as far as we could see. Yet, for these directors, they were considered key within a customer focused business.

RegardingIn terms of how the area of information related to a culture of customer service, companies felt it was important to understanding why clients leave, and that trying to gathering this information before clients after they had-left was crucialtoo late. The importance of collecting data from numerousa number of sources and of internal and external

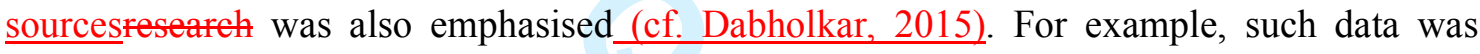
feltdescribed as being "paramount to your business-especially now, I need to know why my customers are leaving, is my offering wrong or are my competitors performing better?" More emphatically, another company said of whether or not to measure if customers were leaving, that "you must be mad if you don't_[measure why clients leave], you need to understand what is going on,-are they leaving because of the recession or are they going somewhere else?" NeverthelessYet, despite these comments, only one of the nine companies actually measured whether their customers left and why, and even then this company did not react to the data they collected. All companies did state, however, that they intended to investigate how to do this as a next step. Interestingly, given the fact that companies felt the intranet and email to be largely ineffective in disseminating information, one company spoke of how they believed a customer service poster that they had on their walls was only "part of the furniture" and generally useless. We argue that the framework we develop here should become a way of working and implementing company strategy, thereby helping with the use of data collected and avoiding the scenario whereby customer service statements become simply "part of the furniture."

\section{Continuous Improvement}


In the area of continuous improvement similar themes emerged as had done so in the areas of Customer Service and Culture, i.e. those of leadership, communications, training, and information again emerged. In terms of leadership, to help ensure continuous improvement in eustomer service, all directors were happy to empower staff but felt controls needed to be in place. to guide staff, They also feltand that the attitude of the customerperson will dictate the employee's attitude to customer service strategy implementation_cf. Kumar Madupalli and Potter, 2014), and that it was the director's responsibility to ensure processes were being adhered to (Baird and Parasnis, 2011) and to establish measurable KPIs. One company noted that ${ }_{2}$ "c Clear values and competencies need to be embedded from the start" and another emphasised that "iff you don't show your staff how you would like them to behave, they will do whatever they think will be suitable" (cf. Li et al., 2015).-

With regard to communications, Aatl companies emphasised the importance of communicating to all employees that customer service is the bedrock of the business and that this should be part of the induction. RegardingWith regard to the use of Twitter and Facebook, all companies agreed that the business environment is changing at a dramatic pace. However, no company was currently considering implementing any controls of the use of email, Twitter, Facebook or Skype, although they did acknowledge the benefits and dangers of these mechanisms. We would expect that since recent changes in social media activities that these media are considered key (Ajnihotri et al, 2015).

All companies agreed that In terms of integrating Customer Service into company training_, all companies agreed that this-should include people skills, and customer service andas well as product knowledge. All companies noted the costs ofinvolved in training in time, money, sales, reputation and effort to retrain underperformers yet. However, companies agreed that this would be cost-efficient if it successful, eded. The absence of training in the past was also noted, one company commenting that "Customer Service wasn't mentioned in my induction". Further, all nine respondents noted the importance of implementing correct and should be ongoing training in skills, knowledge and products (Arya et al. 2003):- Ffor example:-saying that “t Eraining in people skills is vital; it's massively important so why would we train in product knowledge but not in how we treat our customers when they are equally important".

With regard to the role of information in maintaining a customer service focus, Iit was generally felt to be company 'suicide' not to establish what customers_cf. e.g. Rowlands, 2008) and competitors are doing:- As one company noted: "y¥ou need to have data about both sets of customers [(internal and external $)_{2}$ [and $]$ that's why it's important to keep doing 
surveys and research, but act on them, it's company suicide not to find out what your eustomers and competition are up to" (cf. Porter, 1998). The importance of gathering data was stressed by all, but at the same time-however it was noted how the expensive was noted it was to conduct research, and that in a recession it and that it was not always possible to maintain the necessary investment required to keep websites-information up to date, or to keep the company up to daterelevant - on-new processes and technologies. The importance of having the right people on board was again stressed in the area- of information, and the fact that-Eemployees were being asked to do more and more during stressful timestimes of a recession meant that they and may not be as customer focused as required they should be. As Oene company noted: "wHe have lots of information on our customers but we really only look at it if somebody_[i.e. a customer] leaves. We never ask them why, I think it's because people think they will get extra work if we need to change.things." Nevertheless, three companies emphasised that this would not be an issue provided they had employed the right people. Thus, these in-depth interviews confirmed the importance for these directors of gathering customer data and feedback (e.g. Dabholkar, 2015) but they also showed how it was felt insufficient to merely gather data; instead, such data needed to be acted on in order to improve customer retention.

\section{Framework Guide}

On the basis of the first two interviews, the following framework-guide was constructed (see figure 3). This was then taken to the same nine companies, who were then asked for their thoughts about it. The experts were asked their opinion in the final interview as shown below. The key ideas they had are now presented and discussed here under the areas of content and implementation before the final framework, based on these third interviews, is presented.

\section{Insert Figure 3 here}

\section{Framework Content.}

When asked the question 'Does the framework make sense?' $£$ There was consensus that the framework was understood. For exampled. This was borne out through responses such as "it's logically linked and self-challenging", "Absolutely", "It all makes sense and I love the piece about directors showing rather than dictating". Regardingtn terms of suggested modifications, one company suggested that the customer be placed in the centre, by noting the following: "It absolutely makes sense but I would place the customer in the centre, after 
all aren't they the people that are important, then all segments would be running off them, I would move the leaders into the culture section under leadership or management". This was subsequently done (see figure 4 below) and these comments show the advantages of the Delphi technique as the framework was developed from the views and consensus gained (Powell, 2003). Further, some-of the companies then later went on to use some of the findings within their own businesses (see below).

RegardingWith regard to the content of the framework content, when asked the question 'Do you agree or disagree with the frameworks content?' there was a general consensus of agreement. For example, This is illustrated by comments such as "Yes I can't find anything I could disagree with", "Yes I agree with all of it. I find it interesting that we think we are doing all of this until its put in front of you and you realise so much has fallen by the wayside.", "I definitely agree; it's all logically linked", "Completely agree", "It's so full I agree with everything in it?", "I agree with it, I think the big question now is what your company strategy is? Once you have that the rest will fall into place" (cf. Merchant, 2010). TIt is notable that the Delphi technique allowed for in-depth discussion regarding the leadership team's commitment to change, and to their continuous improvement strategies focusing on the gathering and use of data. Without both (cf. Baird and Parasnis, 2011) it is hard to see-how changes can be successfully introduced within businesses. As Porter contends, without leaders fully understanding the direction a company needs to follow, no strategy would be relevant. Thus, good leaders are more important than any strategy (Swaim, 2010, Crosby, 1995).

In terms of the complexity, when asked-of the framework, the underlying theme that eame through in response to the question 'Wwould you consider it a simple or a complex framework and why?' was that it was felteuld to need some initial explanation before it would work. For exampleThis is shown by comments such as "I think the colours should fade into each other", "I think it's simple once you understand how it works, and it can be used in a small area or in total. It gives me somewhere to get started and tells me what I need to consider" (cf. Suzaki, 2002). "It looks big to start with but once you get into it you see there is a lot of cross-over. It shows what you need to focus on, the key indicators and this is important" (cf. Parmanter, 2007). Thus, there was perceived to be a clear benefit of reading the findings in conjunction with the framework to help understand and implement it.

IW With regard to the possibility of the framework working in practice, in response to the question 'Can you see the framework working in practice?' companies agreed that correct management and employee consensus were essential to implement new initiatives, indicating 
a need to encompass all areas of a business as a continuous flow. This also suggests that all areas should be integrated-in order to achieve strategies, avoid communication breakdown, and help businesses achieve optimum performanceperform to their best (Suzaki, 2012; Carroll, 2010; Rowlands, 2008; Deming, 1991). One company believed its viability depended on the buy - in from the management team: "wHithout buy--in you will never get any new initiative into a department let alone a company, we are far too focused on the current trading environment and have completely moved away from focusing on the customers to build our business. In fact we never really focused on our customers, we were ging loans

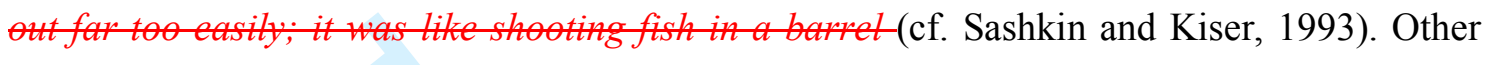
comments related to the effectiveness of the framework, e.g. "Yes it graphically demonstrated what needs to be covered" and an intention to use the framework, e.g. "I intend to take it to my new job; ift will make me look good, coming in with a new idea". Other companies expressed agreement and then talked about how they would implement the framework. One company responded with ${ }_{2}$ "dDefinitely but I would start to implement it by breaking it into departments, giving them each a wheel to work on and get them to feed the results back into the overall Company wheel". It was agreed that, "y¥es it would, but what I would like to see in place first is an analysis of where we currently are, then look at the company strategy and see where the gaps are, then look at how people work and how it all hangs together" (cf. Porter,1995).

WRegarding whether companies felt the framework was missing anything, when asked the question 'Is the framework missing anything?' o-Only one company commented that 'Yes, it's missing the topic finance, I think it's so important it should be in there, if you are not measuring your finances you won't have a business, it feels like it would come under measurements but it should have a heading of its own". No other respondent identified anything missing, although one mentioned that once a company started to use it, then issues may become apparent. It is significant that only one company felt that the framework was missing something, arguably indicating that the Delphi technique's ability to encompass and uncover most areas surrounding a topic. In fact the technique also identified topies of honesty and transparency, neither of which appear to be addressed in the literature.

\section{Framework Implementation}

When asked the question 'How would you then implement it or enable it to work within your business?'-' sSix respondents stated that they would start at the top to introduce the process, and ensure other directors (leaders) were on board before progressing. One stated 
they would tell staff to "JFDI (just $f^{* * * i n g ~ d o ~ i t) ~ e v e r y b o d y ~ n e e d s ~ t o ~ b e ~ o n ~ b o a r d ~ a n d ~ a l l ~}$ working in the one way if they are not on board we need to look at their role within the company and basically get rid" (cf. LaWells, 2009) and one would start by researching their current position in terms of strategy and customer feedback. For example,- " $\underline{m A y}$ directors will love this, we are small enough to agree and implement right away". Also, "I need to get everybody on the one page, that's difficult because of our size therefore I would break it into departments, have the managers develop a plan, that ties them in, and give them support to show them the importance we are placing on it" (cf. Merchant, 2010; Suzaki 2002). "I need to get agreement from the directors and senior managers, this would be a priority, then you could work on a clear strategy, it needs to be very clear, getting the directors to agree will be a challenge"_(cf. Harvard Business Review, 1999). Thus, a key theme was the need to have buy in from management.

WHllustrating this, when asked the question 'Would you see any specific priorities to start with, in the implementation of this framework?'- - a Answers revealed that the right people, communication and company culture were all considered important factors. It was thought that once the decision to start was made then the company needed to have a Customer Service focus and the culture needed to change to be in line- (Soderlund and Rosengren, 2008; Popescu and Diaconu, 2008; Cross, et al., 2007 ). For example:-, it was noted that "People and roles would be my starting point, check if they are right" (cf. Kohli and Jaworski, 1990). Further, one company stated that, "yYou need your team to help with your strategy so talking to them would be a good place to start, need to get them motivated as well" (cf. Wellington, 2010). Similarly, a company noted that "ppeople and mind set change will be the first things to start with; if these are wrong then you are wasting your time" (cf. Harvard Business Review, 1999). AnotherOne company-alse underlined the importance of having all people on board, noting that "gGetting everybody onto the same path, so talking and listening would be important and getting them motivated into doing this would be a pretty key necessity, we would be asking them to change and they need to understand why and knowing them they will ask what's in it for them" (cf. Rowlands, 2008; Dale, 2003; Juergensen 2000). The ability to adopt change is seen to be a challenge amongst business researchers (Taylor, 2010), one of the suggested ways to engage employees is around communication and collaboration at an early stage and ensuring the targets and strategies are aligned. Kaplan and Norton (2006) and Batt (1999) consistently found that self-management worked more effectively for companies than TQM. 
To explore obstacles to implementation, the question 'What would be your biggest hurdle in getting buy-in to implement this framework, if any and why? wWas asked. One company ${ }_{2}$-was based in three culturally different countries, and felt it would be a significant challenginge to get all three sites to understand a companywide customer service policy (cf. Smerd, 2009). Again there was consensus on having the correct people, "jobs worth's, they need to be weeded out, this is an ideal time to do it; wrong people, wrong roles, can affect all areas, they just won't see the vision”. Others feltt the complexity of their business-business complexity would present challenges, for example that "The complexity of our business will be a huge challenge, we would have to divide it into each division, they definitely need this framework, but we are very diverse and big, we would need to find the threads that run through the whole lot and hang the framework off them" (cf. Suzaki, 2002). Company size was felt to be an issue by some. For example, "We are far too big to implement this as a whole; also getting anybody to agree to changes at this point will be testing". Furthermore, getting people on board was felt to be an obstacle, for example that,. One company said that "gGetting agreement and peoples attitude to change are two great big hurdles, so it's back to having the right people, they don't normally fight change and usually see the benefits", orFurther, a second company noted that "I see the hurdles being internal staff resistance and getting them to agree to change their ways". Company size clearly affects ability to change as the challenge of communicating a) to the whole company, b) keeping the same message and c) attaining the same understanding is immense (Kaplan and Norton, 2006; Crosby 1995). Yet, breaking the task into manageable pieces, attaining agreement, and using a collaborative approach is most likely an effective starting point (Taylor, 2010; Parmenter, 2007; Van de Berg, 2007).

\section{The final framework.}

Based on the third interviews and the comments from companies the final framework is presented here below in Figure $\underline{4 X}$. This integrates all the ideas from the literature, from the first two interviews, and, significantly ${ }_{2}$ changes the central section from 'leadership' to 'customer focused leadership' to reflect the companies' comments.

\section{Insert Figure 4 here}


Although the model still remains to be tested, in the final third interviews a number of directors shed light on how the model could be used practically by commenting both on how they intended to use it in practice, and also on how they had already started to implement it. $\underline{\text { Regarding intentions, one company felt they would now commence a review of those who }}$ were underperforming and, "move them along", and that they felt more confident to improve TQM in the company after hearing of others' experiences. Another company felt that they had neglected customer service for a long time and intended to use the framework to refocus on it, and three companies stated how they now intended to use customer service performance measures as part of their quarterly employee reviews and would attempt to implement this into their business if they can get internal agreement. Regarding actual changes, one company had now moved away from using the intranet and email when launching in-company initiatives to the use of personal communications with department heads. Also, two companies were in the process of compiling a list of KPIs specifically in customer service as a test to see how their teams would react were they to introduce a complete customer service culture. Thus, companies were drawing on and implementing the model by the time of the third interview.

\section{Conclusions}

This article describes the development of a framework for companies to use to integrate a customer retention focused work ethic throughout their companies. This involved exploring three areas of Continuous Improvement (CI), Customer Service, and Culture through in-depth Delphi-technique style interviews with nine company directors.

RegardingIn terms of Customer Service, the strategy should be simple to understand and must be holistic. Further, it should become the basis of a company's core values and its delivery part of the company's performance measures. It requires having the right person to represent a company (both nationally and internationally) as key to the success of any business regardless of the role. Furthermore, the 1 Leadership was considered fundamental to any-cultural changes, not to dictate, but to spend time 'at the coalface' to understand everyday processes and occurring issues. This would then have a fourfold effect that employees feltet they weare being listened to; directors understoodand the workings of the business; strategies, targets and relevant initiatives can be developed and; collaboration at all levels assists in the implementation of new initiatives. RegardingWith regard to research and information, measuring sales alone was regarded as insufficient, whereas measuringement of the number of departing clients and reviewing why they left was considered a better 
indication of success, and a review of why they left should be included. Customer service delivery can be used as a measure for employee development and career progression; delivery of this can be linked to salaries, bonuses and promotion.

Regarding how information is communicated, a straightforward, clear and focused strategy is required that includes processes allowing for open communications including feedback. It is thus necessary to create and maintain an environment where employees feel confident to discuss issues and initiatives in open discussion, meetings, training, and mentoring.

Regarding continuous improvement, 'responsibility' was considered key. It was felt all employees should understand-the company needs and their responsibility towards delivering excellent customer service; this must be communicated from induction and monitored on a regular basis. Companies should show commitment to customer service delivery and include customer service policies and strategies at induction, and by example. Retraining was consideredis seen as more cost effective than dismissal and rehiring.

By amalgamating a continuous improvement initiative and a customer service strategy, processes become holistic, involving every department inand by implementing a continuous circle of communication where information is shared and used. In the areas of

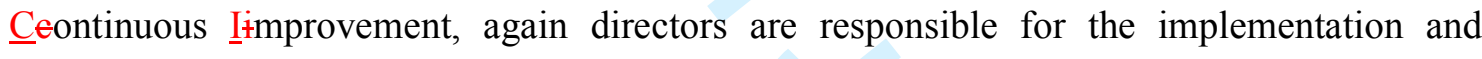
success of procedures. Where the business is considered too large to implement a holistic implementation of the new framework, breaking it into departments and feeding into an overall company initiative could be considered.

Clearly, the above article shows links between Customer Service, and Continuous Improvement, and Culture.and, through the use of the Delphi technique, it shows the importance of the areas of finance, IT, and business improvement models. Theoretically, the above findings arguably show that the main area for consideration was that a CI initiative considers quality improvement tools. Some existingsuch tools include the customer; however, they have been criticised for not going far enough in looking after the customer (e.g. Dale, 2003; Lagrosen, 2001; McQuarter et al., 1995).- If they did, as the above article and framework show, these two topics would arguably merge even further. In Customer Service it is maintained that profit will follow good service, whilst in $\mathrm{CI}_{2}$ profit is not seen to be so important $_{2} \overline{5}_{-}-$the customer is the important factor. Theoretically, and significantly, these statements may actually align.

The above results show that the developed framework to align these elements is simple and uncomplicated to understand when used in conjunction with clear explanations. 
However, until a time when the framework is tested in practice it is difficult to say with any certainty how easy it would be to implement. This is both a limitation and an area should form part of anyfor future research-undertaken. Implementing-changes within any business changes is not-usually-an easy task, and requires planning and communications throughout the company. For example, tThe size and culture of a company also dictates the uptake of any initiative and although there is consensus here that this framework will work, consideration must be given to the amount of potential change possiblythat may be required; spanning anything from director buy-in to process change, attitudes, skills, training, people's ability to change, empowerment or leadership and of course costs. The framework may need to be adapted to individual companies depending on these elements. Nevertheless, whatever the context, we argue the framework demonstrates that when a holistic approach is implemented, regardless of size or industry, it showsBy doing this it is hoped that it is possible to demonstrate that when-a customer service is the focus ${ }_{2}$ - f the heart and ethos of the company culture and is embedded throughout all elements of company practice and culture, then the improvement to TQM is both tangible and significant.

Overall the use of the Delphi technique in the context of the existing models and existing literature to interview company directors reveals a number of novel and significant elements for integrating the three key areas of CI, Customer Service and Culture.- Firstly rather than having a single customer focused department or section ${ }_{2}$ in order to truly focus on the customer it must be introduced holistically throughout the whole company, secondly the fundamental role played by the people in the company was noted, and this has to be considered at all stages of company processes including recruitment, training and openness to feedback. Finally and most importantly this paper shows that without being supported and driven by the leadership of the company a customer retention focused ethos will not result.

\section{References}

\section{Agnihotri, R., Dingus, R., Hu, M. Y., \& Krush, M. T. (2015). Social media: Influencing} customer satisfaction in B2B sales. Industrial Marketing Management.

Alvesson, M., \& Sveningsson, S. (2015). Changing organizational culture: Cultural change work in progress. Routledge.

Anderson, K. Kerr. C. (2003). Customer Relationships. McGraw Hill New York USA. Arya, S. Sharma, D. Nagarajan, S. Kaushal, V. (2003). Job redesigning - key to cost containment and TQM in hospitals. Journal of the Academy of Hospital 
Administrations, Vol. 15. No. 1, pp. 39-41.

Assarlind, M., Gremyr, I., \& Bäckman, K. (2013). Multi-faceted views on a Lean Six Sigma application. International Journal of Quality \& Reliability Management, 30(4), 387$\underline{402 .}$

Asif, M. Joost de Bruijn, E. Douglas, A. Fisscher, O. (2009). Why quality management programs fail: A strategic and operations management perspective. International Journal of Quality \& Reliability Management Vol. 26. Issue: 8. pp. 778 - 794

Aula, P., \& Heinonen, J. (2016). Extended Culture. In The Reputable Firm (pp. 99-119). Springer International Publishing.

Baird,C. Parasnis, G. (2011). From social media to social customer relationship management. Strategy and Leadership, Vol. 39. Issue: 5, pp. 30-37.

Batt, R. (1999). Work Organisation, Technology and Performance in Customer Service and Sales. 52.4 Industrial and Labour Relations Review. pp. 539 -564 Heinonline, Buffalo USA.

Berry, L. (1995). Relationship marketing of services: growing interest, emerging perspectives. Journal of Academy of Marketing Science, Vol. 23. No. 4, pp. 1-2

Berry, L. Parasuraman, A. (1991). Marketing Services: Competing Through Quality. The Free Press, New York, USA,

Bienstock, C. C., Mentzer, J. T., \& Kahn, K. B. (2015). How are Service Firms Measuring and Managing Service Quality/Customer Satisfaction?. In Proceedings of the 1996 Academy of Marketing Science (AMS) Annual Conference (pp. 161-161). Springer International Publishing.

Browne, B. (1968). A methodology used in the elicitation of opinions of experts. The Rand Corporation Santa Monica California.

Buelens. M, Kreitner, R. Kinicki, A. (2002). Organisational Behaviour. 2nd European Edition. McGraw Hill Education. Berkshire.

Calabrese, A., \& Scoglio, F. (2012). Reframing the past: A new approach in service quality assessment. Total Quality Management \& Business Excellence, 23(11-12), 13291343.

Cao, J., Jiang, Z., \& Wang, K. (2015). Customer demand prediction of service-oriented manufacturing incorporating customer satisfaction. International Journal of Production Research, 1-19.

Carroll, N. (2010). The Communication Problem Solver: Tools and techniques of busy managers. American Management Association. New York. USA. 
Carter, M. Z., Armenakis, A. A., Feild, H. S., \& Mossholder, K. W. (2013). Transformational leadership, relationship quality, and employee performance during continuous incremental organizational change. Journal of Organizational Behavior, 34(7), 942 $\underline{958 .}$

Chakravorti, S. (2011). Managing organizational culture change and knowledge to enhance customer experiences: analysis and framework. Journal of Strategic Marketing, 19(02), 123-151.

Champney. J. (1995) .Re-engineering Management. The Mandate for New Leadership. Harper Collins. New York.

Chaneski, W S (2015) On the Right Track to Continuous Improvement. Modern Machine Shop $88.1: 42,44$.

Chidley, J., \& Pritchard, N. (2014). Drivers for creating value and enhancing customer experience through people. Industrial and Commercial Training, 46(6), 293-301.

Conway, N., \& Briner, R. B. (2015). Unit-level linkages between employee commitment to the organization, customer service delivery and customer satisfaction. The International Journal of Human Resource Management, 26(16), 2039-2061.

Cook, S. (2008). Customer Care Excellence. 5th edition Kogan Page Ltd. London UK.

Crosby, P. (1995). Quality is Still Free, Making Quality Certain in Uncertain Times.

McGraw Hill. New York. USA.

Cross, M. Brashear, T. Rigdom, E. Bellenger, D.N. (2007). Customer orientation and salesperson performance. European Journal of Marketing, Vol. 41. Nos. 7/8, pp. $821-835$

Cudney, E. Elrod, C. Kovach, J. (2010). An Empirical Evaluation of the Effectiveness of Continuous Improvement Techniques. IEE Annual conference proceedings.

Dabholkar, P. A. (2015). How to improve perceived service quality by increasing customer participation. In Proceedings of the 1990 Academy of Marketing Science (AMS) Annual Conference (pp. 483-487). Springer International Publishing.

Daffy, C. (2001). Once a customer always a customer. $3^{\text {rd }}$ edition. Oak Tree Press. Dublin. Dahlgaard, J. Dahlgaard-Park, S. (2006). Lean production, six sigma quality, TQM and company culture. The TQM Magazine, Vol. 18. Issue: 3. pp. 263-281. Emerald Publishing Group.

Dale, B. (2003). Managing Quality. 4th edition, Blackwell Publishing, London.

Deming. W. (2000, 1982). Out of the crisis. MIT Press. Massachusetts. USA.

Deming. W. (2000). The new Economics. - For Industry, Economics and Education. MIT Press. Massachusetts. USA. 
Deming, W. (1991). Out of the Crisis. Massachusetts Institute of Technology, Centre for Advanced Engineering Study, Cambridge, Massachusetts. USA.

Ennew, C. T., Binks, M. R., \& Chiplin, B. (2015). Customer Satisfaction and Customer Retention: An Examination of Small Businesses and Their Banks in the UK. In Proceedings of the 1994 Academy of Marketing Science (AMS) Annual Conference (pp. 188-192). Springer International Publishing.

Gîfu, D., \& Teodorescu, M. (2014). Communication process in a Lean concept. International Letters of Social and Humanistic Sciences (ILSHS), 17, 119-127.

Gimenez-Espin, J. A., Jiménez-Jiménez, D., \& Martínez-Costa, M. (2013). Organizational culture for total quality management. Total Quality Management \& Business Excellence, 24(5-6), 678-692.

Godfrey, A. Stephens, K. Wadsworth, H. (2002). Modern methods for quality control and improvement. John Wiley and Sons Inc, Massachusetts.

Gratton, L. Hope Hailey, V. Stiles, P. Truss, C. (2003). Strategic Human Resource, Management. Oxford. University Press Oxford.

Green, T. J. (2012). TQM and organisational culture: How do they link?. Total Quality Management \& Business Excellence, 23(2), 141-157.

Gremler, D. Gwinner, K. Brown, S. (2001). Generating positive word-of-mouth communication through customer-employee relationships. International Journal of Service Industries Management, Vol. 12. No. 1, pp. 44.

Griffin, A., Gleason, G., Preiss, R., \& Shevenaugh, D. (2012). Best practice for customer satisfaction in manufacturing firms. Sloan Management Review, 36(2).

Gupta, A (2016) Customer Service: A key Differentiator in Retailing. In Kamath, N and Saurav, S. The Handbook of Research in Strategic Supply Chain Management in the Retail Industry. USA Business Science: IGI Global pp.75-87

Gupta, U. Clarke, R. (1996). Theory and Applications of the Delphi Technique. Technology Forecasting and Social Change, Elsevier Sciences. New York. USA.

Gustafsson, A., McColl-Kennedy, J., J. Sirianni, N., \& K. Tse, D. (2014). Small details that make big differences: A radical approach to consumption experience as a firm's differentiating strategy. Journal of Service Management, 25(2), 253-274.

Haren, A (2005) Development of a framework to retain customers through CRM. Dublin Institute of Technology. Available at: http://www.comp.dit.ie/rfitzpatrick/mscpublications/2205 angela haren_pdf

Heskett, J. Sasser, W. Schlesinger, L. (1997). The service profit chain. The Free Press. New York. USA. 
Harvard Business Review on Corporate Strategy (1999). Collis and Montgomery: Creating Corporate Advantage. Harvard Business School Press. Boston, USA.

Hur, W. M., Moon, T. W., \& Jung, Y. S. (2015). Customer response to employee emotional labor: the structural relationship between emotional labor, job satisfaction, and customer satisfaction. Journal of Services Marketing, 29(1), 71-80.

Irani ,Z. Beskese, A, Love, P. (2004). Total quality management and corporate culture: constructs of organisational excellence. Technovation Elsevier, Vol. 24, Issue 8, pp. 643-650

Ishikawa, K. (1990). Introduction to Quality Control. Chapman Hall, London.

Ireland, Hoskisson, Hitt. (2012). Understanding Business Strategy. South-Western Cengage Learning. Mason USA.

Johnson, C. C. (2015). Organisational culture and the experience of negative emotions on counterproductive workplace behaviours (Doctoral dissertation, faculty of Humanities, University of the Witwatersrand).

Juergensen, T. (2000). Continuous Improvement: Mindsets, Capabilities, Process, Tools and Results. The Juergensen Consulting Group, Inc, Indianapolis, USA.

Juran, J. (1989). Juran on Leadership for Quality. Free Press, Simon and Schuster New York. USA.

Juran, J. (2005) A century of Improvement. Volume 15. Quality Press Milwaukee USA. Kaplan, R. Norton, D. (2006). How to Implement a New Strategy without Disrupting Your Organisation. Harvard Business School Publishing. Boston. USA.

Kaufman, R. (2015). Why Your Customer Service Training Won't Lead to Happy Customers (or Inspired Employees). The Journal for Quality and Participation, 37(4), 33.

Kee-Hung, H. Cheng, T. (2009). Just In Time Logistics. Gower Publishing Ltd, Surrey. UK.

Kohlbacher, M., \& Reijers, H. A. (2013). The effects of process-oriented organizational design on firm performance. Business Process Management Journal, 19(2), 245-262.

Kohli, A. Jaworski, B. (1990). Market orientation: the construct, research propositions and managerial implications. Journal of Marketing, Vol. 54. No. 2, pp. 1

Kumar Madupalli, R., \& Poddar, A. (2014). Problematic customers and customer service employee retaliation. Journal of services marketing, 28(3), 244-255.

Lages, C. R., \& Piercy, N. F. (2012). Key drivers of frontline employee generation of ideas for customer service improvement. Journal of Service Research, 1094670511436005.

Lagrosen, S. (2001). Strengthening the weakest link of TQM - from customer focus to customer understanding. The TQM Magazine Vol. 13.5, pp. 348-354. 
Lam, M., O'Donnell, M., \& Robertson, D. (2015). Achieving employee commitment for continuous improvement initiatives. International Journal of Operations \& Production Management, 35(2), 201-215.

Laureani, A. Antony, J. Douglas, A. (2010). Lean six sigma in a call centre: a case study. International Journal of Productivity and Performance Management, Vol. 59. Issue 8. pp. 757-768.

Laursen, G. Thorlund, J. (2010). Business Analytics for Managers, Taking Business Intelligence beyond reporting. J. Wiley and Sons New Jersey USA.

Leatherman, R. (2008). Quality Leadership Skills. Standards of leadership behaviour. HRD Press Inc, Massachusetts USA.

Li, J., Luo, J., \& Qin, H. (2015). The Impact of Employees' Reaction on Customer Satisfaction in Failed Compatibility Management. In LISS 2013 (pp. 939-943). Springer Berlin Heidelberg.

Löfving, M., Säfsten, K., \& Winroth, M. (2016). Leadership style, organisational culture and manufacturing strategy formulation. International Journal of Manufacturing Technology and Management (IJMTM).

Marsh, J. (1998). The Continuous Improvement Toolkit. A Practical Resource for Achieving Organisational Excellence. B.T Batsford Ltd. London. UK.

Merchant, N. (2010). The New How: Creating Business Solutions Through Collaborative Strategy. O Reilly Media California, USA.

McQuarter, R. Scurr, C. Dale, B. Hillman, P. (1995). Using quality tools and techniques successful. The TQM Magazine, Vol. 7. No. 6, pp. 37-42

Mintel. (1999). Special report on customer retention in the financial market. Mintel. London. UK.

Mobley, W. Wang, Y. Li, M. (2009). Advances in Global Leadership. Vol. 5. Emerald Group Publishing, Bingley UK.

Oliver, R. (1999). The shape of things to come. McGraw Hill. New York.

Parast, M. M. (2011). The effect of Six Sigma projects on innovation and firm performance. International Journal of Project Management, 29(1), 45-55.

Pantouvakis, A., \& Bouranta, N. (2013). The link between organizational learning culture and customer satisfaction: Confirming relationship and exploring moderating effect. The Learning Organization, 20(1), 48-64.

Parmenter, D. (2007). Key Performance Indicators: Developing, Implementing and Using Winning KPI's. John Wiley and Sons New Jersey, USA.

Popescu, C. Diaconu, L. (2008). Human Capital and Innovation. Training and Development. Alexandria VA. USA.

Porter, M. (1998). Competitive Strategy: Techniques for Analysing Industries and 
Competitors. The Free Press New York USA.

Powell, C. (2003). The Delphi Technique: Myths and Realities. Blackwell Publishing. Journal of Advanced Nursing. Vol. 41, pp. 376-382. UK.

Pride, W. Hughes, R. Kapoor, J. (2008). Business. South-Western Cengage Learning. Mason USA.

$\underline{\text { Rawson, A., Duncan, E., \& Jones, C. (2013). Touchpoints matter, but it's the full journey that }}$ really counts. HARVARD BUSINESS REVIEW, 91(9), 90-+.

Rezaei, G., Gholami, H., Shaharou, A. B. M., Zameri Mat Saman, M., Sadeghi, L., \& Zakuan, N. (2015). Shared knowledge mediated correlation between cultural excellence and organisational performance. Total Quality Management \& Business Excellence, 1-32.

Rich, D. (2009). Create your own upturn. Customer Relationship Marketing Journal, Vol. 13. Issue: 10, pp. 14-15. Medford.

Rowe, G. Wright, G. (2001.) Expert opinions in forecasting. The role of the Delphi technique. In J. Armstrong principles of forecasting, pp. 122-144. Boston Kluwer Academy. USA.

Rowlands, A. (2008). TQM. Author House. Milton Keynes UK.

Saarijärvi, H., Grönroos, C., \& Kuusela, H. (2014). Reverse use of customer data: implications for service-based business models. Journal of Services Marketing, 28(7), 529-537.

Saizarbitoria I, H., Arana Landín, G., \& Casadesús Fa, M. (2006). A Delphi study on motivation for ISO 9000 and EFQM. International Journal of Quality \& Reliability Management, 23(7), 807-827.

Saizarbitoria, I. H. (2006). How quality management models influence company resultsconclusions of an empirical study based on the Delphi method. Total Quality Management \& Business Excellence, 17(6), 775-794.

Salkind, N. (2010). Encyclopaedia of Research Design. Sage Publications Ltd. London.

Sashkin, M. Kiser, K. (1993). Putting total quality management to work. Berret-Koehler San Francisco. USA.

Schein, E. (2004). Organisational Culture and Leadership. J Wiley and Sons. Chichester

Sleep, S., Bharadwaj, S., \& Lam, S. K. (2015). Walking a tightrope: the joint impact of customer and within-firm boundary spanning activities on perceived customer satisfaction and team performance. Journal of the Academy of Marketing Science, 43(4), 472-489.

Smerd, J. (2009). A Stalled Cultural change. Workforce Management. Vol. 88. No 13. 
pp. not listed. Costa Mesa. USA.

Söderlund, M. Rosengren, S. (2008). Revisiting the smiling service worker and customer satisfaction. International Journal of Service Industry Management. Vol. 19. Issue: 5, pp. 552-574.

Suzaki, K. (2012). The new manufacturing challenge. Techniques for continuous improvement. The Free Press. Simon and Schuster Inc. N.Y. USA.

Suzaki, K. (2002). Results from the heart. How mini company management captures everyone's talents and helps them to find meaning and purpose at work. The Free Press. Simon and Schuster Inc. N.Y. USA.

Swaim, R. (2010). The Strategic Drucker: Growth Strategies and Marketing Insights from the works of Peter Drucker. John Wiles and Sons (Asia) Singapore.

Tayfon, J. (2006). New Auto Survey Floor Traffic Survey Answers Auto Dealer's Million Dollar Question: Why Do Customers Leave? Business Wire. New York.

Taylor, M. (2010). Accelerating Business: How to Accelerate the Implementation and Adoption. iUniverse, Bloomington. N.Y. USA

Taylor, Y. (2008). The tip of the iceberg. Working on the Victoria Climbie data corpus project. Qualitative Research 8 (1): 115 - 135

Teche, R. (1990). Qualitative Research. Analysis types and software tools. Vol. 337, Falmer Press. London. UK.

Thompson, B. (2005). The loyalty connection: Secrets to customer retention and increased profits. CRMGURU.com, Right now technologies. Montana, USA.

Thomas, L. (2003). Irresistible Businesses: Dazzling and Delighting Customers for Life. iUniverse. Lincoln. USA.

US Chamber of commerce and US Small Business Administration. (2006). $\mathrm{http}$ //www.focusedmarketing.info/customers/why-do-customers-leave.html.

Van de Berg, J. (2007). Integral Warehouse The next generation in transparency collaboration and warehouse systems management. Management Outlook Publications. The Netherlands.

Want, J. (2003). Corporate Culture, Illuminating the Black Hole. Organisational Strategies Intl. USA.

Webster, C., \& White, A. (2010). Exploring the national and organizational culture mix in service firms. Journal of the Academy of Marketing Science, 38(6), 691-703.

Wellington, P. (2010). Effective customer care. Kogan Page Ltd London UK.

Williams, C. (2008). Effective management. Thompson Higher Education. Mason USA. 
Womack, J. Jones, D. (2003). Lean thinking: Banish waste and create wealth in your corporation. The Free Press. Simon and Schuster Inc. N.Y. USA.

Woudenberg, F. (1991). An Evaluation of Delphi. Elsevier Science Publishing Co., Inc. Amsterdam. Holland.

Yang, Y., Lee, P. K., \& Cheng, T. C. E. (2016). Continuous improvement competence, employee creativity, and new service development performance: A frontline employee perspective. International Journal of Production Economics, 171, 275-288.

Zeithaml, V. Parasuraman, A. Berry, L. (1990). Delivering Quality Service: Balancing Customer Perceptions and Expectations. The Free Press. New York. 